\title{
Feeding Your Baby ${ }^{1}$
}

\author{
Linda B. Bobroff and Nicole Owens Duffy ${ }^{2}$
}

\section{Introduction}

Feeding your baby is one of the first things you do as a parent. It's also one of the ways that you develop a relationship with this new family member. When feeding goes well, everyone in the family is happier.

The information in this publication can help you develop a close feeding relationship with your baby. The skills you learn will also help you and your child avoid conflicts over food during the toddler and preschool years.

\section{Getting Close to Baby}

Your relationship with your baby begins as soon as he or she is born. You communicate with your little one when you hold him or her as you nurse or bottle-feed. Parents and caregivers let babies know that they love them by learning what their different cries mean and responding to their needs. You can never "spoil" infants by holding them and answering their cries with your attention.

The way you handle feeding is an important part of communicating your love to your new baby. Feeding infants "on demand" helps them feel safe and loved.

\section{Sharing Responsibility}

Did you ever think about sharing the responsibility for feeding with your baby? It may sound strange, but both you and your baby have a role to play in feeding! Let's look at your role in feeding and see what your baby's role is. This

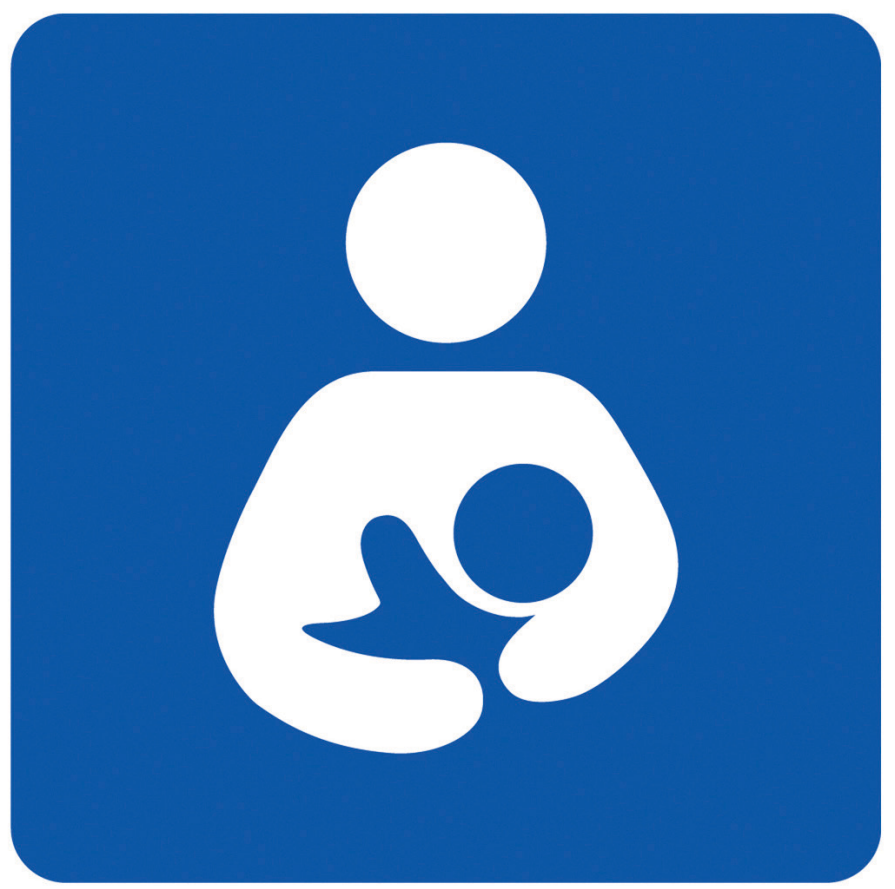

Figure 1. International breastfeeding symbol.

Credits: Public domain image designed by Matt Daigle / Source: http://www.mothering.com/breastfeeding-symbol-downloads

will help you stay focused on only your part and will make feeding a relaxing time for you and your baby.

\section{Parent's Role}

What is your role in feeding? Simply put, you are responsible for offering healthy, age-appropriate foods in a friendly and loving way.

1. This document is FCS8545, one of a series of the Department of Family, Youth and Community Sciences, UF/IFAS Extension. Original publication date January 1998. Revised March 2019. Visit the EDIS website at https://edis.ifas.ufl.edu for the currently supported version of this publication.

2. Linda B. Bobroff, PhD, RDN, professor emerita; and Nicole Owens Duffy, state specialized agent, Department of Family, Youth and Community Sciences; UF/IFAS Extension, Gainesville, FL 32611. 
Notice that the word we use is "offering," not "getting him or her to eat." Offer nutritious and easy-to-eat food, and let your baby take it from there. For infants under about six months of age, the only necessary food is breast milk. If breastfeeding is not possible or you choose not to breastfeed, then you can use iron-fortified infant formula. When your baby seems hungry, offer breast, or a bottle (with pumped breast milk or formula) and see what happens. Hungry babies are eager to latch on to the breast or suck on the bottle. When bottle-feeding, it can take a few tries to find a bottle that your baby will latch on to. Try not to be discouraged if latching on is a challenge for your baby.

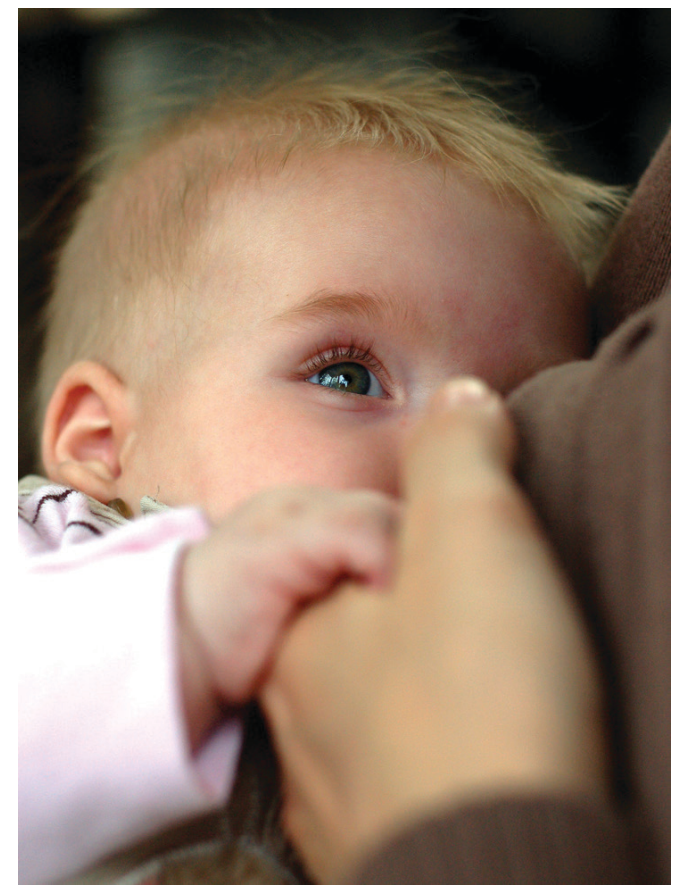

Figure 2. Breastfeeding / Emzirme \#4 Credits: Ozgur Poyrazoglu / License: CC BY-NC-SA 2.0 / Source: http:// flic.kr/p/4eXKMp

\section{Baby's Role}

What is your baby's role in the feeding relationship? Give your baby the chance to decide how much he or she will eat, and even if your baby will eat at all. After all, who knows best when baby is hungry? Baby does, of course.

Babies also know when they have had enough and want to stop eating. If we pay attention, we can respond to their cue and end feeding time. Even if there is expressed breast milk or formula left in the bottle, stop feeding when baby is done. Always discard leftover milk.

Feeding is more straightforward when we let baby decide when to eat and when to stop. The perfect time to feed babies is when they act hungry. Babies will turn their head toward your body (rooting) or start fussing. When they are very hungry, you will hear that special "I'm hungry" cry.
The perfect time to stop feeding is when baby turns his or her head away and seems uninterested. Your baby will let you know when it is time to eat again.

Feeding your baby on demand may be inconvenient, but it will not last forever. Feeding on demand is only for the first year. When your infant becomes a toddler, you will start to plan meal and snack times. But for the first year, let baby's hunger be your guide.

\section{Baby's Best Start Feeding Infants Breast Milk}

Breast milk is the perfect first food for babies because it is made for human infants. A few advantages of breast milk are:

- Proper nutrient composition;

- Easy digestibility; and

- Immune factors that help to keep your baby healthy.

A few advantages of breastfeeding are:

- Inexpensiveness;

- Convenience;

- Help with maternal weight loss; and

- Natural support of a close mother-baby bond.

\section{Bottle-Feeding}

Infant formula or expressed breast milk can be provided in a bottle. Bottle-feeding expressed breast milk has the same nutritional advantages as breastfeeding. Infant formula is a recommended substitute for breast milk when breastfeeding is not possible or preferable. Infant formula is recommended if a mother has an inadequate diet or uses alcohol or drugs.

Advantages of bottle-feeding are:

- Opportunities for other family members to feed baby;

- Fewer restrictions for some moms; and

- Avoidance of barriers to breastfeeding at work or in public.

When using formula, be sure to only use formula that is especially designed for infants. Do NOT use evaporated milk or fortified soy beverages. Powdered formulas cost less than those that are ready-to-eat. Follow label directions on the package very carefully. NEVER dilute infant formula to 
make it last longer. This can slow your baby's growth and development and is VERY dangerous.

To develop closeness with your baby while bottle-feeding:

- Hold your baby securely but not too tightly.

- Look at him or her and smile.

- Speak softly to your baby.

- Stop feeding when baby turns his or her head away, cries, or squirms.

- Burp baby gently.

- Offer the bottle again after soothing or burping your baby. Let baby decide whether or not to eat more.

- DO NOT leave your baby with a bottle propped in his or her mouth. Babies need to be held while they eat to feel secure.

- NEVER put anything but infant formula, breast milk, or water in a bottle.

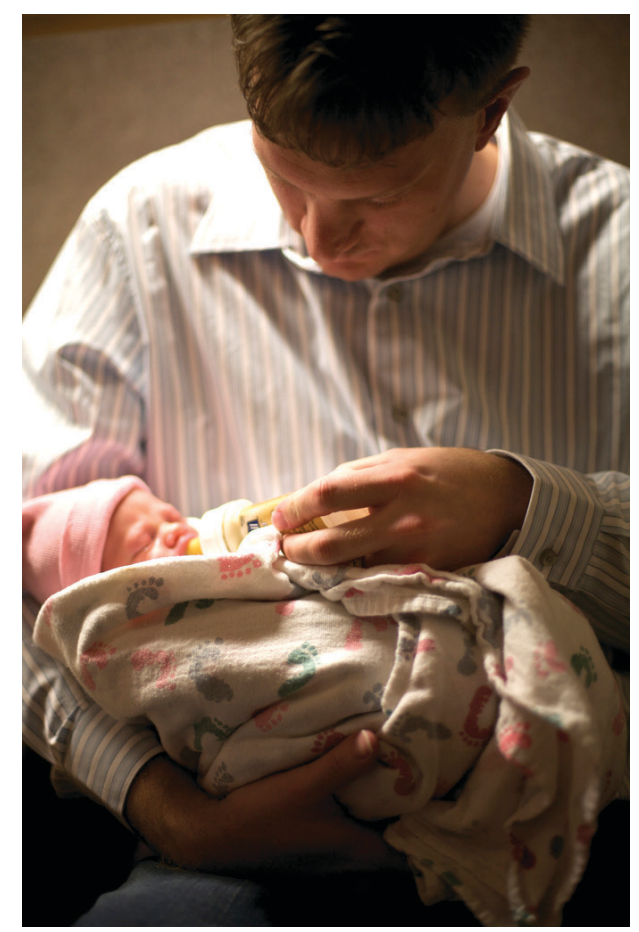

Figure 3. "Dad will feed you."

Credits: Ryan Grimm / License: CC BY-ND 2.0 / Source: http://flic. $\mathrm{kr} / \mathrm{p} / 7 \mathrm{qXoGY}$

Whether you feed your baby breast milk or infant formula, you can have a close and happy relationship by following the suggestions above.

Keep in mind that neither difficult times nor wonderful times last forever. Enjoy every minute with your new baby-they grow up so fast!
For more information about infant feeding, contact your local UF/IFAS Extension Family and Consumer Sciences (FCS) educator. UF/IFAS Extension offices are listed at http://sfyl.ifas.ufl.edu/find-your-local-office/. A WIC nutritionist can be contacted through your county Health Department. For referral to a registered dietitian (RD or RDN) in your area, click on "Find an Expert" at http://www. eatright.org. In Florida, you can call the Florida Academy of Nutrition and Dietetics at (850) 386-8850.

\section{Recommended Reading}

Satter, E. (2014). Feeding with Love and Good Sense. Ellyn Satter Institute. Retrieved from www.EllynSatterInstitute. org

Satter, E. (1987). How to Get Your Kid to Eat... But Not Too Much. Boulder: Bull Publishing Company.

\section{Recommended Websites}

FoodSafety.gov-A guide to keep baby food and infant formula safe for your baby. http://www.foodsafety.gov/keep/ types/babyfood/

Centers for Disease Control and Prevention-Information on breastfeeding guidelines, recommendations, special circumstances, and more. https://www.cdc.gov/breastfeeding/index.htm

MedlinePlus-US National Library of Medicine and National Institutes of Health. Providing research-based information for consumers and professionals in all aspects of health, this website is devoted to basic nutrition and health issues as well as cutting edge research and news related to infant and toddler care. http://www.nlm.nih.gov/ medlineplus/childrenshealth.html/

WomensHealth.gov-US Department of Health and $\mathrm{Hu}-$ man Services, Office on Women's Health. This site provides reliable information related to women's health, pregnancy, and breastfeeding. Materials are available in English and Spanish. http://www.womenshealth.gov/. 